\title{
Roles of Subthreshold Calcium Current and Sodium Current in Spontaneous Firing of Mouse Midbrain Dopamine Neurons
}

\author{
Michelino Puopolo, Elio Raviola, and Bruce P. Bean \\ Department of Neurobiology, Harvard Medical School, Boston, Massachusetts 02115
}

We used a preparation of acutely dissociated neurons to quantify the ionic currents driving the spontaneous firing of substantia nigra pars compacta neurons, isolated from transgenic mice in which the tyrosine hydroxylase promoter drives expression of human placental alkaline phosphatase (PLAP) on the outer surface of the cell membrane. Dissociated neurons identified by fluorescent antibodies to PLAP showed firing properties similar to those of dopaminergic neurons in brain slice, including rhythmic spontaneous firing of broad action potentials and, in some cells, rhythmic oscillatory activity in the presence of tetrodotoxin (TTX). Spontaneous activity in TTX had broader, smaller spikes than normal pacemaking and was stopped by removal of external calcium. Normal pacemaking was also consistently silenced by replacement of external calcium by cobalt and was slowed by more specific calcium channel blockers. Nimodipine produced a slowing of pacemaking frequency. Pacemaking was also slowed by the P/Q-channel blocker $\omega$-Aga-IVA, but the N-type channel blocker $\omega$-conotoxin GVIA had no effect. In voltage-clamp experiments, using records of pacemaking as command voltage, cobalt-sensitive current and TTX-sensitive current were both sizeable at subthreshold voltages between spikes. Cobalt-sensitive current was consistently larger than TTX-sensitive current at interspike voltages from -70 to $-50 \mathrm{mV}$, with TTX-sensitive current larger at voltages positive to $-45 \mathrm{mV}$. These results support previous evidence for a major role of voltage-dependent calcium channels in driving pacemaking of midbrain dopamine neurons and suggest that multiple calcium channel types contribute to this function. The results also show a significant contribution of subthreshold TTX-sensitive sodium current.

Key words: pacemaker currents; substantia nigra; sodium current; calcium current; $I_{\mathrm{h}}$; nimodipine; tyrosine hydroxylase

\section{Introduction}

Midbrain dopaminergic neurons play an important role in many brain functions, including motor control, motivation, reward, and cognition (Nieoullon, 2002; Schultz, 2002; Wise, 2004). Dysfunction of the dopaminergic system is involved in many neurological disorders, including Parkinson's disease, schizophrenia, and drug addiction (Koob et al., 1998; Lewis and Lieberman, 2000; Dauer and Przedborski, 2003). Midbrain dopamine neurons are spontaneously active (Grace and Bunney, 1984) and tonic firing is likely important for maintaining background dopamine levels in target areas.

Spontaneous activity of midbrain dopaminergic neurons apparently relies on a different ionic mechanism than most other pacemaking cells in the CNS. Blocking the hyperpolarizationactivated cation current $I_{\mathrm{h}}$ has no effect on pacemaking in most midbrain dopamine neurons (Mercuri et al., 1995), although in a subpopulation of neurons, pacemaking is slowed but not stopped (Seutin et al., 2001; Neuhoff et al., 2002). In contrast to most other pacemaking neurons in the CNS where blocking calcium entry has little effect on pacemaking or even speeds it (Llinás and Alonso, 1992; Takakusaki and Kitai, 1997; Bevan and Wilson,

\footnotetext{
Received 0ct. 4, 2006; revised Dec. 8, 2006; accepted Dec. 14, 2006. This work was supported by National Institutes of Health Grants NS36855 and EY01344.

Correspondence should be addressed to Bruce P. Bean, Department of Neurobiology, Harvard Medical School, 220 Longwood Avenue, Boston, MA 02115. E-mail: bruce_bean@hms.harvard.edu. DOI:10.1523/JNEUROSCI.4341-06.2007

Copyright $\odot 2007$ Society for Neuroscience $\quad$ 0270-6474/07/270645-12\$15.00/0
}

1999; Raman and Bean, 1999; Beurrier et al., 2000; Do and Bean, 2003), midbrain dopamine neurons are unusual in that blocking calcium current by cadmium or cobalt completely silences pacemaking (Fujimura and Matsuda, 1989; Grace and Onn, 1989; Harris et al., 1989). In a powerful experimental approach combining calcium imaging with voltage clamp, Wilson and Callaway (2000) showed that a subthreshold calcium current in midbrain dopamine neurons activates steeply over the voltage range from -60 to $-30 \mathrm{mV}$ and shows little inactivation (in contrast to expectations from low-threshold T-type current). Voltage clamp in dissociated neurons shows the existence of multiple components of calcium current, including L-type, N-type, and P/Q-type currents (Cardozo and Bean, 1995; Durante et al., 2004). The calcium current involved in pacemaking is probably at least partly L-type current, because pacemaking is slowed or stopped by L-type channel blockers but not N-type channel blockers (Nedergaard et al., 1993; Mercuri et al., 1994) (but see Fujimura and Matsuda, 1989; Kang and Kitai, 1993b). P/Q-type channel blockers have not yet been tested on pacemaking. Also, the possible role of subthreshold TTX-sensitive sodium current in pacemaking of midbrain dopamine neurons has received little attention, although it drives pacemaking of many other neuronal pacemakers (Pennartz et al., 1997; Bevan and Wilson, 1999; Raman and Bean, 1999; Taddese and Bean, 2002).

We have examined the currents driving pacemaking of midbrain dopamine neurons using the action potential clamp method, in which records of pacemaking activity are used as the 
voltage command in voltage-clamp experiments and currents flowing during the interspike interval can be directly quantified. Consistent with a dominant role of calcium current in pacemaking, we found a sizeable interspike current sensitive to replacement of extracellular calcium by cobalt. TTX-sensitive sodium current also contributes significant charge entry during the interspike interval. Surprisingly, the selective P/Q-channel blocker $\omega$-Aga-IVA had a dramatic effect in slowing or stopping pacemaking.

\section{Materials and Methods}

Preparation of acutely dissociated neurons. Acutely dissociated neurons were obtained from transgenic mice (14-18 d old) in which catecholaminergic neurons in the CNS express human placental alkaline phosphatase (PLAP) on the outer surface of the cell membrane (Gustincich et al., 1997). After anesthesia and decapitation, the brain was removed and placed in ice-cold dissociation medium consisting of the following (in mM): $82 \mathrm{Na}_{2} \mathrm{SO}_{4}, 30 \mathrm{~K}_{2} \mathrm{SO}_{4}, 5 \mathrm{MgCl}_{2}, 10$ glucose, $10 \mathrm{HEPES}$, and $0.001 \%$ phenol red indicator; $\mathrm{pH}$ was adjusted to 7.4 with $\mathrm{NaOH}$ and the solution was continuously bubbled with $100 \% \mathrm{O}_{2}$. The brain was cut into $400 \mu \mathrm{m}$ coronal slices with a vibrating tissue slicer. The region containing the substantia nigra pars compacta $(\mathrm{SNc})$ was dissected out from the slices and incubated in dissociation medium containing 3 $\mathrm{mg} / \mathrm{ml}$ protease type XXIII (Sigma, St. Louis, MO) for 30-40 min at $35^{\circ} \mathrm{C}$. After enzymatic digestion, the tissue was washed with dissociation medium containing $1 \mathrm{mg} / \mathrm{ml}$ bovine serum albumin (Sigma) and 1 $\mathrm{mg} / \mathrm{ml}$ trypsin inhibitor (Sigma) and triturated using fire-polished Pasteur pipettes of varying bores. The resulting cell suspensions were centrifuged at $1000 \mathrm{rpm}$ for $3 \mathrm{~min}$ and the pellet was resuspended in Tyrode's solution. The dissociated neurons were directly plated on the glass bottom of concanavalin A-coated $(1 \mathrm{mg} / \mathrm{ml})$ recording chambers and kept at room temperature at least $1 \mathrm{~h}$ before commencement of recordings. $\mathrm{SNc}$ neurons were identified by labeling of their membrane with a monoclonal antibody to PLAP (De Groote et al., 1983) directly conjugated to the fluorochrome Cy3 (E6-Cy3). E6-Cy3-stained SNc neurons were identified by scanning the coverslip with an inverted microscope (Diaphot 300; Nikon, Tokyo, Japan) equipped with epifluorescence. After identification of a PLAP-positive cell, the remaining procedures were performed using visible light with Nomarski optics.

Preparation of brain slices. Black Swiss mice (14-42 d old) were anesthetized with isofluorane. After decapitation, the brain was removed and placed in ice-cold artificial CSF (ACSF) enriched with sucrose. This solution, referred as slicing solution, consisted of the following (in $\mathrm{mM}$ ): 87 $\mathrm{NaCl}, 2.5 \mathrm{KCl}, 1.25 \mathrm{NaH}_{2} \mathrm{PO}_{4}, 26 \mathrm{NaHCO}_{3}, 1 \mathrm{MgCl}_{2}, 20$ glucose, and 75 sucrose, continuously bubbled with $95 \% \mathrm{O}_{2} / 5 \% \mathrm{CO}_{2}$. Coronal slices $(200-250 \mu \mathrm{m})$ containing the substantia nigra were obtained using a vibrating tissue slicer (DTK-1000; DSK, Dosaka, Japan). Slices were then held at room temperature in the slicing solution supplemented with 0.5 $\mathrm{mM} \mathrm{CaCl}_{2}$. For recordings, slices were transferred to a recording chamber and mounted on the stage of an upright microscope (Nikon E600FN). Neurons were visualized using infrared differential interference contrast videomicroscopy (DAGE-MTI, Michigan City, IN). We targeted neurons with large cell bodies located near the ventrolateral margin of the $\mathrm{SNc}$ (i.e., close to the margin between the $\mathrm{SNc}$ and substantia nigra pars reticulata and far from the ventral tegmental area). Slices were continuously perfused at a rate of $2 \mathrm{ml} / \mathrm{min}$ with ACSF consisting of the following (in mM): $125 \mathrm{NaCl}, 2.5 \mathrm{KCl}, 1.25 \mathrm{NaH}_{2} \mathrm{PO}_{4}, 26 \mathrm{NaHCO}_{3}, 2 \mathrm{CaCl}_{2}, 1$ $\mathrm{MgCl}_{2}$, and 20 glucose, bubbled with $95 \% \mathrm{O}_{2} / 5 \% \mathrm{CO}_{2}$.

Electrophysiology. Recordings in dissociated cells were made using an Axopatch 200B amplifier (Molecular Devices, Foster City, CA). The resistance of the patch pipettes filled with internal solution was 2.5-3.5 $\mathrm{M} \Omega$. The patch pipettes were wrapped to near the tip with stretched Parafilm to reduce capacitance. In voltage-clamp experiments, the series resistance of the pipettes was 5-10 $\mathrm{M} \Omega$ and was compensated up to $\sim 80 \%$. Current-clamp recordings were performed in the fast currentclamp mode to reduce distortion of action potentials (Magistretti et al., 1996, 1998). Current and voltage traces were low-pass-filtered at $2-5 \mathrm{kHz}$ using the internal Bessel filter of the amplifier and sampled at 20-100 $\mu$ s.
Recordings in brain slice were made using a MultiClamp 700B amplifier (Molecular Devices) using pipettes of resistance 1.3-1.8 $\mathrm{M} \Omega$, wrapped with Parafilm to reduce capacitance. In voltage-clamp experiments, the series resistance of the pipettes was compensated by $30-40 \%$.

Solutions and pharmacology. For recordings in isolated cells, unless noted otherwise, the extracellular solution for current-clamp recordings contained the following (in $\mathrm{mm}$ ): $137 \mathrm{NaCl}, 5.4 \mathrm{KCl}, 1.8 \mathrm{CaCl}_{2}, 1 \mathrm{MgCl}_{2}$, 5 HEPES, and 10 glucose, $\mathrm{pH}$ adjusted to 7.4 with $\mathrm{NaOH}$. The intracellular solution contained the following (in mM): $120 \mathrm{~K}$-gluconate, $6 \mathrm{NaCl}$, $4 \mathrm{MgCl}_{2}, 2 \mathrm{Mg}$-ATP, $0.3 \mathrm{Na}-\mathrm{GTP}, 14$ phosphocreatine, 5 EGTA, 0.5 $\mathrm{CaCl}_{2}, 10$ glucose, and 10 HEPES, pH adjusted to 7.2 with $\mathrm{KOH}$. In some of the experiments with nimodipine, $\mathrm{KMeSO}_{4}$ (ICN Pharmaceuticals, Costa Mesa, CA) was substituted for K-gluconate. Sodium current was obtained as the current sensitive to $1 \mu \mathrm{M}$ TTX with most voltagedependent potassium and calcium currents blocked with an extracellular solution containing the following (in mM): $137 \mathrm{NaCl}, 1.8 \mathrm{CoCl}_{2}, 1 \mathrm{MgCl}_{2}$, 5.4 tetraethylammonium (TEA)-Cl, 10 4-aminopyridine, 5 HEPES, and 10 glucose, $\mathrm{pH}$ adjusted to 7.4 with $\mathrm{NaOH}$. To determine calcium currents, equimolar cobalt was substituted for calcium in an extracellular solution containing the following (in $\mathrm{mM}$ ): $137 \mathrm{NaCl}, 1.8 \mathrm{CaCl}_{2}, 1 \mathrm{MgCl}_{2}$, 5.4 TEA-Cl, 10 4-aminopyridine, 5 HEPES, 10 glucose, and $1 \mu \mathrm{M}$ TTX, $\mathrm{pH}$ adjusted to 7.4 with $\mathrm{NaOH}$.

A stock solution of TTX (Research Biochemicals, Natick, MA) was made in $2 \mathrm{~mm}$ citric acid and stored at $-20^{\circ} \mathrm{C}$. Nimodipine (Research Biochemicals) was prepared as a $50 \mathrm{~mm}$ stock solution in polyethylene glycol and kept at $4^{\circ} \mathrm{C}$. ZD 7288 was obtained from Tocris Bioscience (Bristol, UK) and prepared as a $10 \mathrm{~mm}$ stock solution in water. For cells in which ZD 7288 had no effect on firing, there were always other cells studied the same day in which the same ZD 7288 solution did affect firing, providing a positive control. $\omega$-Conotoxin GVIA and $\omega$-Aga-IVA (Peptides International, Louisville, KY) were prepared as a $1000 \times$ stock solution in water and kept at $4^{\circ} \mathrm{C}$. Drugs were diluted to a final concentration in the extracellular solution before the experiment and applied onto the cell by gravity flow through an array of microcapillary tubes controlled by a rapid solution changer (RSC-200; Biologic, Claix, France). Solution exchange was complete in $<1$ s. $\omega$-Aga-IVA was applied at a concentration of $200 \mathrm{~nm}$. $\omega$-Aga-IVA was applied without the addition of cytochrome $\mathrm{C}$, often included to reduce adsorption of toxin to perfusion tubing (Mintz et al., 1992). A control experiment recording voltage-clamped calcium current in a cerebellar Purkinje neuron showed that application of $200 \mathrm{~nm} \omega$-Aga-IVA applied without cytochrome C (using the same perfusion apparatus used in studying the dopaminergic neurons) produced a saturating block of P-type current, with no additional effect after switching to $200 \mathrm{~nm} \omega$-Aga-IVA plus $1 \mathrm{mg} / \mathrm{ml}$ cytochrome $\mathrm{C}$. Thus, although we cannot rule out some reduction in effective toxin concentration caused by adsorption to tubing, the toxin delivered was sufficient to completely block P-type calcium channels.

For slice recordings, slices were continuously perfused with ACSF. Seal and whole-cell configuration were obtained in ACSF. Afterward, the experiment was performed using HEPES-based extracellular solutions applied locally in the vicinity of the cell. Synaptic transmission was blocked by supplementing the extracellular solution with kynurenic acid $(2 \mathrm{~mm})$ and picrotoxin $(50 \mu \mathrm{M})$. The extracellular solution for currentclamp recordings consisted of the following (in $\mathrm{mm}$ ): $151 \mathrm{NaCl}, 2.5 \mathrm{KCl}$, $2 \mathrm{CaCl}_{2}, 1 \mathrm{MgCl}_{2}, 10$ HEPES, and 13 glucose, with $\mathrm{pH}$ adjusted to 7.4 with $\mathrm{NaOH}$. The intracellular solution contained the following (in $\mathrm{mm}$ ): 135 K-Methanesulfonate, $10 \mathrm{NaCl}, 2 \mathrm{MgCl}_{2}$, 4 Mg-ATP, $0.3 \mathrm{Na}$-GTP, 14 phosphocreatine, $0.1 \mathrm{EGTA}$, and $10 \mathrm{HEPES}$, with $\mathrm{pH}$ adjusted to 7.2 with $\mathrm{KOH}$. In voltage clamp, sodium current was isolated by determination of the current sensitive to $1 \mu \mathrm{M}$ TTX in a solution consisting of the following (in mM): $151 \mathrm{NaCl}, 2.5 \mathrm{KCl}, 2 \mathrm{CoCl}_{2}, 1 \mathrm{MgCl}_{2}, 15$ TEA-Cl, 10 HEPES, and 13 glucose, $\mathrm{pH}$ adjusted to 7.4 with $\mathrm{NaOH}$. Calcium current was determined by substitution of equimolar cobalt for calcium in an extracellular solution containing the following (in mM): $151 \mathrm{NaCl}, 2.5 \mathrm{KCl}, 15$ TEA$\mathrm{Cl}, 2 \mathrm{CaCl}_{2}, 1 \mathrm{MgCl}_{2}, 10$ HEPES, 13 glucose, and $1 \mu \mathrm{M}$ TTX, pH adjusted to 7.4 with $\mathrm{NaOH}$. In some experiments on neurons in brain slice, cobalt substitution for calcium was done on a background of a solution in which TEA fully replaced sodium [(in mM): 153.5 TEA-Cl, $2 \mathrm{CaCl}_{2}, 1 \mathrm{MgCl}_{2}, 10$ HEPES, 13 glucose, and $1 \mu \mathrm{M}$ TTX, pH adjusted to 7.4 with $\mathrm{NaOH}$ ], 
which might in principle better isolate calcium currents by blocking calcium-activated potassium currents more fully (as well as any currents carried by sodium that might be affected by cobalt for calcium substitution). However, recordings were less stable under these conditions, and there was little difference in the voltage dependence or magnitude of the interspike cobalt-sensitive current between experiments done with a background of $151 \mathrm{~mm} \mathrm{NaCl}$ and $15 \mathrm{~mm}$ TEA-Cl [17 $\pm 2 \mathrm{pC}$, integrated from the afterhyperpolarization to $-50 \mathrm{mV}$; postnatal day 35 (P35)-P42; $n=8]$ and those done with a background of 153.5 TEA-Cl (14 $\pm 2 \mathrm{pC}$; $\mathrm{P} 35-\mathrm{P} 42 ; n=8)$. Therefore, the values for brain slice experiments given in the text are confined to experiments done with a background of 151 $\mathrm{mm} \mathrm{NaCl}$ and 15 mm TEA-Cl.

All of the experiments were performed at room temperature $(22 \pm$ $\left.2^{\circ} \mathrm{C}\right)$.

Acquisition and analysis. Data acquisition was made by using pClamp 8 or 9 (Molecular Devices) and data analysis was performed using Clampfit 8 (Molecular Devices) and IgorPro version 3.14 (WaveMetrics, Lake Oswego, OR). Reported voltages were corrected for junction potential between the internal solution and the extracellular solution measured using a flowing $3 \mathrm{M} \mathrm{KCl}$ electrode as described by Neher (1992). Data are presented as mean \pm SEM.

Immunocytochemistry. Mouse brains were perfused with $2 \%$ formaldehyde in 0.15 м Sörensen phosphate buffer, $\mathrm{pH} 7.4$, cryoprotected in $20 \%$ sucrose, and frozen in partially solidified dichlorodifluoromethane kept in liquid nitrogen. Cryostat sections were blocked in 10\% normal goat serum (Vector Laboratories, Burlingame, CA), 2\% fish gelatin (Goldmark Biologicals, Phillipsburg, NJ), and $0.2 \%$ bovine serum albumin (Sigma) in PBS for $1 \mathrm{~h}$. They were incubated overnight in mouse monoclonal to tyrosine hydroxylase (TH) (Immunostar, Hudson, WI) 1:1000 in block solution, followed by Alexa Fluor goat anti-mouse IgG (Invitrogen, Eugene, OR) 1:500 in block solution.

For immunocytochemistry on acutely dissociated neurons, neurons were plated on a coverslip, fixed with $0.5 \%$ formaldehyde in $0.15 \mathrm{M}$ Sörensen phosphate buffer, $\mathrm{pH}$ 7.4, washed in block solution containing $0.3 \%$ Triton X-100, and treated with a mixture of 1:100 E6 anti-human monoclonal antibody to PLAP (Gustincich et al., 1997) directly conjugated to Cy3 and 1:500 polyclonal sheep antibody to TH (Novus Biologicals, Littleton, CO) in block solution. Secondary antibody was Alexa Fluor 488 donkey anti-sheep IgG (Invitrogen) 1:500.

For demonstration of PLAP activity, vibratome sections of the fixed midbrain were warmed up to $65^{\circ} \mathrm{C}$ for $30 \mathrm{~min}$ in PBS to inactivate other phosphatases. They were subsequently incubated in the dark for $3 \mathrm{~h}$ in $0.1 \%$ 5-bromo-4-chloro-3-indolyl phosphate (Invitrogen) and 1\% nitroblue tetrazolium in $0.1 \mathrm{M}$ Tris- $\mathrm{HCl}$ buffer, $\mathrm{pH} 9.5$, containing $0.1 \mathrm{M}$ $\mathrm{NaCl}$ and $0.05 \mathrm{M} \mathrm{MgCl}_{2}$. After rinsing with $0.02 \mathrm{M}$ EDTA in PBS, the sections were mounted in a polyvinyl alcohol resin (Vinol Grade 205; Air Products and Chemicals, Allentown, PA).

Images were captured by using a Nikon Eclipse E600 microscope equipped with a SPOT RT Slider camera (Diagnostic Instruments, Sterling Heights, MI).

\section{Results}

\section{Properties of spontaneous firing in dissociated neurons}

Previous work has shown strong involvement of calcium current in generating the spontaneous firing of dopaminergic neurons in the SNc (Grace and Onn, 1989; Harris et al., 1989; Yung et al., 1991; Nedergaard and Greenfield, 1992; Kang and Kitai, 1993a,b; Nedergaard et al., 1993; Mercuri et al., 1994; Ping and Shepard, 1996; Wilson and Callaway, 2000). Also, dopaminergic SNc neurons express prominent $I_{\mathrm{h}}$, which appears to make a significant contribution to pacemaking in a subpopulation of midbrain dopamine neurons (Neuhoff et al., 2002). The calcium current driving pacemaking in midbrain dopamine neurons appears to be especially prominent in the dendrites of the cells (Wilson and Callaway, 2000), and in some types of neurons, including hippocampal and cortical pyramidal neurons, $I_{\mathrm{h}}$ is also present at higher density in dendrites than in cell bodies (Magee, 1998;
Williams and Stuart, 2000; Lorincz et al., 2002; Kole et al., 2006). This makes it uncertain whether the ionic mechanism of pacemaking can fruitfully be studied in dissociated neurons, which have the advantage of allowing higher-fidelity voltage clamp and faster solution exchange but the potential disadvantage of lacking most of the dendritic tree. Therefore, we first tested how well the basic properties of pacemaking are preserved in dissociated neurons by examining how spontaneous firing of dissociated cells is affected by block of $I_{\mathrm{h}}$, calcium current, and sodium current, all of which have been studied previously using dopaminergic neurons in brain slice.

To identify acutely dissociated SNc neurons, we used a transgenic mouse line in which catecholaminergic neurons in the CNS express PLAP on the outer surface of the cell membrane (Gustincich et al., 1997). The line was obtained by introducing into the mouse genome PLAP cDNA linked to a promoter sequence of the gene for tyrosine hydroxylase (Banerjee et al., 1992). Figure 1 illustrates the location and morphology of midbrain dopaminergic neurons expressing PLAP and compares expression of the transgene with tyrosine hydroxylase expression. Cells staining for PLAP (Fig. $1 A, C$ ) were also labeled by antibodies to tyrosine hydroxylase (Fig. $1 B$ ) and vice versa. Similarly, after enzymatic digestion and mechanical trituration of the SNc, a population of isolated neurons were stained by both a monoclonal antibody to PLAP directly conjugated to the Cy3 fluorophore (Fig. 1D, left) and by antibodies to tyrosine hydroxylase (Fig. $1 D$, middle). Because PLAP resides on the external surface of the membrane, living unfixed dopaminergic neurons could be fluorescently labeled by the monoclonal Cy3-conjugated antibody after the neurons were dissociated from the SNc. This allowed electrophysiological recording from identified dopaminergic neurons.

Labeled dissociated neurons were spontaneously active in the cell-attached configuration, as evidenced by regular action currents when the pipette was sealed onto the cell. After breaking the cell membrane and switching to whole-cell current-clamp configuration, the vast majority of neurons continued to fire spontaneously (Fig. 2). Spontaneous firing in acutely dissociated neurons occurred with an average rate of $3.4 \pm 0.1 \mathrm{~Hz}(n=62)$ and was usually quite rhythmic, with an average coefficient of variation of interspike intervals of $45 \pm 4 \%(n=62)$. Spikes reached an average peak of $+31 \pm 1 \mathrm{mV}$ and had an afterhyperpolarization averaging $-64 \pm 1 \mathrm{mV}(n=62)$. Action potentials were broad (width at half-maximum amplitude, $3.1 \pm 0.1 \mathrm{~ms} ; n=62$ ) with a prominent shoulder.

These results show that dissociated neurons retain the ionic machinery necessary to produce spontaneous pacemaking and are consistent with previous studies showing that pacemaking activity can be retained in acutely dissociated dopaminergic neurons (Hainsworth et al., 1991; Cardozo and Bean, 1995). In fact, pacemaking in the dissociated neurons is somewhat faster than is typical in brain slice recordings at room temperature $(1-2 \mathrm{~Hz})$. To see whether the basic ionic properties of pacemaking are similar in dissociated cells as in brain slice, we examined the effects on pacemaking of blocking $I_{\mathrm{h}}$, calcium current, and sodium current. First, we tested the effect of blocking $I_{\mathrm{h}}$ by ZD 7288 (Fig. 2). Two different populations of neurons could be distinguished based on the effects of ZD 7288. In 17 of 22 neurons tested, $30 \mu \mathrm{M}$ ZD 7288 produced a clear slowing of firing (Fig. $2 A$ ), by an average of $52 \pm$ $6 \%$. The slowing of firing was accompanied by a small hyperpolarization (measured at the trough, by $-1.1 \pm 0.2 \mathrm{mV}$ ), as expected from block of an inward current carried by $I_{\mathrm{h}}$ between spikes. In the other five of the 22 neurons tested (Fig. 2C), ZD 7288 had no effect on firing rate (change of $+2 \pm 5 \%$ ) and either 
had no effect on interspike voltage or produced a small depolarization (average change in trough by $+1.2 \pm 0.4 \mathrm{mV}$ in these five cells).

These results are consistent with previous reports of two distinct populations of $\mathrm{SNc}$ dopaminergic neurons studied in brain slice, one in which ZD 7288 slows firing by $\sim 40 \%$ and one in which ZD 7288 has no effect (Seutin et al., 2001; Neuhoff et al., 2002; see also Mercuri et al., 1995). Neuhoff et al. (2002) found that the two populations of SNc neurons showing differential responses to ZD 7288 had different current densities of $I_{\mathrm{h}}$ and could also be distinguished by the timing of rebound firing after a hyperpolarizing current pulse, with those responding to ZD 7288 showing a shorter latency to firing. We saw the same correlation in dissociated neurons. The dissociated neurons in which ZD 7288 slowed spontaneous firing (Fig. 2A,B) had an average latency to firing of $229 \pm 18 \mathrm{~ms}$ ( $n=17$ ), considerably faster than the group of neurons (Fig. 2C,D) in which ZD 7288 did not affect firing $(854 \pm 55 \mathrm{~ms}$; $n=5)$.

These results show that spontaneous firing in dissociated neurons is affected by ZD 7288 in a very similar manner as for intact cells studied in brain slice. The dissociated neurons clearly retain substantial $I_{\mathrm{h}}$, because all neurons (even those in which firing was not affected by ZD 7288) showed the characteristic sag in voltage during hyperpolarizing current pulses (Fig. 2D). This sag was always blocked by ZD $7288(30 \mu \mathrm{M}$, seven of seven cells tested.) The results show that $I_{\mathrm{h}}$ channels survive dissociation and are expressed in the parts of the cell (soma and proximal dendrites) retained during dissociation. However, it is notable that in no cell did blocking $I_{\mathrm{h}}$ completely stop firing, suggesting that even when $I_{\mathrm{h}}$ contributes to spontaneous firing, it never plays an essential role. This again is identical with the results in brain slice (Mercuri et al., 1995; Seutin et al., 2001; Neuhoff et al., 2002).

We next tested the effects of blocking voltage-dependent calcium current on pacemaking. To rapidly block currents from all of the multiple calcium channel types known to be present in $\mathrm{SNc}$ dopaminergic neurons (Cardozo and Bean, 1995; Durante et al., 2004), we replaced external calcium by equimolar cobalt. In many other pacemaking central neurons, including cerebellar Purkinje neurons (Raman and Bean, 1999), suprachiasmatic nucleus neurons (Pennartz et al., 1997; Jackson et al., 2004), and subthalamic nucleus neurons (Bevan and Wilson, 1999; Beurrier et al., 2000; Do and Bean, 2003), this manipulation has little or no effect on firing rate or even speeds firing, apparently by blocking calcium-activated potassium channels. In $\mathrm{SNc}$ dopaminergic neurons, however, substituting cobalt for calcium consistently stopped spontaneous firing (Fig. 3). Total block of spontaneous firing was seen in 17 of 17 cells tested. The effect was immediate with the solution change $(<1 \mathrm{~s})$ and the cessation of firing was accompanied by a hyperpolarization, consistent with direct electrical effect attributable to inhibition of inward calcium current flowing during the interspike interval rather than a second messenger-mediated response secondary to a change in intracellular calcium levels. Cobalt substitution for calcium hyperpolarized the membrane potential of neurons (measured as the average potential between spikes) by $-7 \pm 2 \mathrm{mV}(n=17)$, from $-59 \pm 1 \mathrm{mV}$ in control to $-66 \pm 3 \mathrm{mV}$ after the replacement of calcium. In some cells, like that in Figure 3, the hyperpolarization was so pronounced that after cessation of firing the resting potential was negative even to the maximum afterhyperpolarization during control pacemaking. Thus, although SNc dopaminergic neurons have small-conductance calcium-activated potassium (SK) channels, producing substantial SK current, expected to be present between spikes (Nedergaard et al., 1993), the net interspike current sensitive to removal of calcium is inward. This is in striking contrast to other central neurons, including Purkinje neurons, subthalamic nucleus neurons, and suprachiasmatic nucleus neurons.

We next examined the effects of blocking voltage-dependent sodium channels. Previously, it has been found that, although TTX blocks the fast overshooting spikes during pacemaking of 

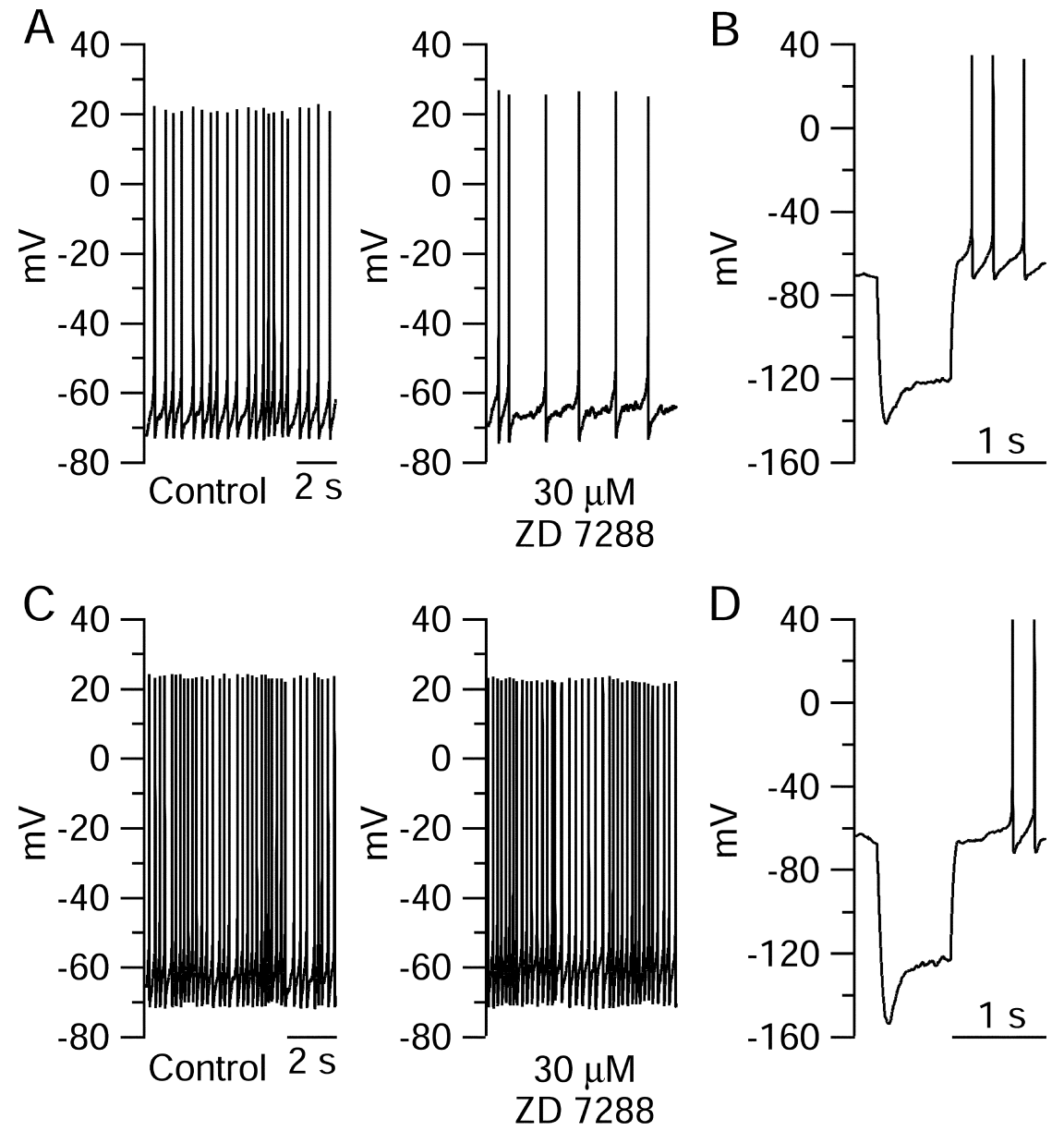

Figure 2. Effect of the $I_{\mathrm{h}}$ blocker ZD 7288 on pacemaking in dissociated SNc dopaminergic neurons. $\boldsymbol{A}$, Left, Pacemaking in an acutely dissociated dopaminergic neuron from the TH-PLAP transgenic mouse line identified by Cy3-conjugated antibody to PLAP. Right, Spontaneous firing in the same cell after application of $30 \mu \mathrm{m}$ ZD 7288. $\boldsymbol{B}$, Response of this cell to hyperpolarizing current pulse ( $-80 \mathrm{pA}$ current injection, before application of ZD 7228). C, Lack of effect on pacemaking of ZD 7288 applied in a different acutely dissociated neuron (also identified as dopaminergic neuron by antibody to PLAP). $\boldsymbol{D}$, Response of this cell to hyperpolarizing current pulse ( $-80 \mathrm{pA}$ current injection, before ZD 7288).

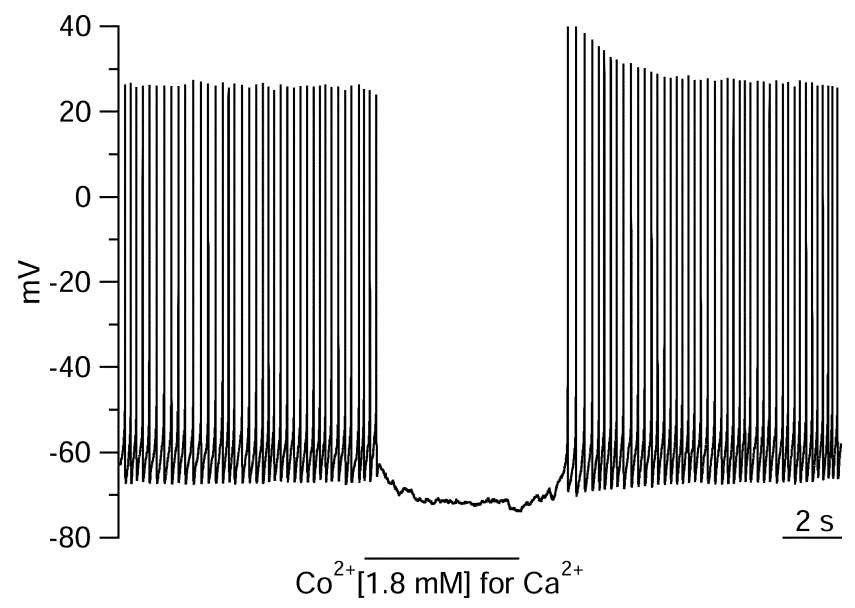

Figure 3. Effect of blocking calcium entry on pacemaking in a dissociated SNc dopaminergic neuron. Immediate hyperpolarization and cessation of pacemaking on switching to an external solution in which cobalt replaced calcium is evident.

SNc neurons, in some neurons the cell membrane potential continues to oscillate in the presence of TTX (Fujimura and Matsuda, 1989; Yung et al., 1991; Nedergaard and Greenfield, 1992; Nedergaard et al. 1993; Wilson and Callaway, 2000). These oscilla- tions are calcium-dependent and, at least in some cases, occur at a frequency similar to the frequency of spontaneous firing of full-blown spikes under control conditions, as if normal pacemaking is driven by an underlying oscillation whose depolarizing phase is entirely attributable to calcium current. In a variety of other types of pacemaking neurons, including dopaminergic neurons in the retina and in the olfactory bulb (Feigenspan et al., 1998; Steffen et al., 2003; Puopolo et al., 2005), there appears to be a strong contribution from subthreshold "persistent" sodium current to the spontaneous depolarization between spikes. It has been argued that subthreshold persistent sodium current might necessarily be present in all neurons that have large transient sodium currents (Taddese and Bean, 2002) (but see Astman et al., 2006). If so, it might be expected to contribute significantly to the spontaneous depolarization underlying pacemaking in $\mathrm{SNc}$ dopaminergic neurons.

As for other manipulations, we saw very similar effects of TTX on pacemaking in dissociated neurons as reported previously for neurons in slice. In some cells, TTX produced complete quiescence. An example is shown in Figure 4A, where firing stopped abruptly $(<1 \mathrm{~s})$ on application of TTX. In this and the other cells in which spontaneous activity was stopped by TTX, the membrane potential in TTX stabilized at a value $(-64 \pm 2 \mathrm{mV})$ considerably hyperpolarized relative to the average interspike voltage of the cells before TTX $(-58 \pm 1 \mathrm{mV} ; n=10)$. Hyperpolarization to a relatively steady membrane potential was seen in 14 of 21 cells exposed to TTX. In the other seven cells, spontaneous activity continued after application of TTX, with smaller, broader action potentials arising from more depolarized interspike voltages. An example is shown in Figure $4 B$. In this cell, the firing frequency changed only slightly in the presence of TTX, but spikes were smaller and broader and the average interspike voltage shifted in the depolarizing direction, from -57 to $-53 \mathrm{mV}$. In cells in which spontaneous oscillatory activity continued in the presence of TTX, it was consistent that spikes were smaller (average peak of $+31 \pm 3 \mathrm{mV}$ in control, $-4 \pm 5 \mathrm{mV}$ in TTX), much broader (width at halfmaximum of $3.1 \pm 0.6 \mathrm{~ms}$ in control, $8.2 \pm 0.7 \mathrm{~ms}$ in TTX), and had depolarized interspike voltages $(-58 \pm 2 \mathrm{mV}$ in control, $-50 \pm 1 \mathrm{mV}$ in TTX). However, the direction of change of the frequency of spontaneous activity was inconsistent, ranging from slowing by $27 \%$ to speeding by $41 \%$. This suggests complex effects in different directions that can sometimes result in very little change in the frequency, as in Figure $4 B$. When present, the spontaneous activity in TTX was always (seven of seven cells) stopped by cobalt substitution for calcium (Fig. 4C).

Like the effects of blocking $I_{\mathrm{h}}$, the ability of spontaneous oscillatory activity to continue in the presence of TTX is consistent with previous experiments with $\mathrm{SNc}$ neurons in brain slice (Nedergaard et al., 1993, Wilson and Callaway, 2000). These results 

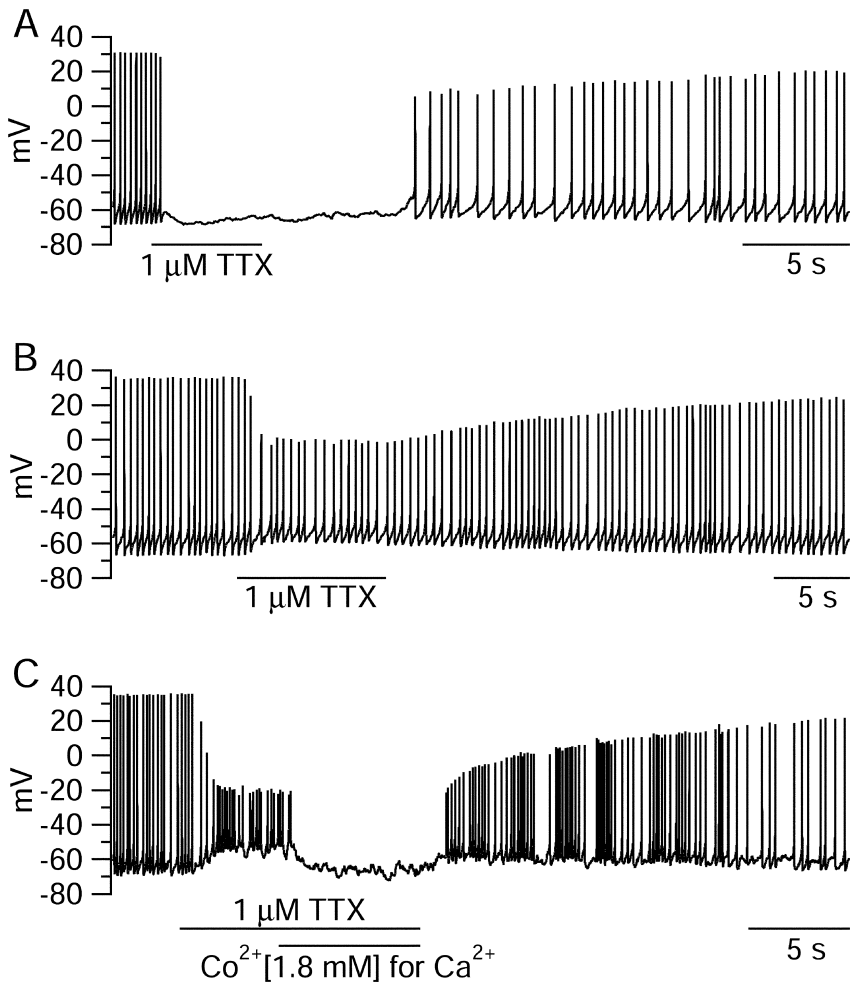

Figure 4. Effect of TTX on spontaneous activity in dissociated SNc neurons. $A$, Hyperpolarization and cessation of pacemaking on application of TTX to a dissociated SNc neuron. $\boldsymbol{B}$, Effect of TTX on spontaneous activity in another dissociated SNc neuron in which spontaneous activity continued, with smaller and broader spikes from a more depolarized potential. C, Effect of cobalt substitution for calcium on spontaneous activity seen in TTX in another dissociated neuron.

suggest that pacemaking in dissociated SNc neurons has very similar characteristics as seen for intact neurons in brain slice. In particular, the dissociated neurons apparently retain contributions from calcium channels and from $I_{\mathrm{h}}$ (in a subpopulation of neurons) similar to those seen in slice experiments. The similarity of pacemaking in dissociated neurons and brain slice neurons encouraged us to perform voltage-clamp experiments using dissociated neurons aimed at quantifying the relative roles of interspike calcium current and TTX-sensitive sodium current. To do this, we used the action potential clamp method (Llinás et al., 1982), using signal-averaging to resolve the relatively small currents flowing in between spikes (Zaza et al., 1997; Taddese and Bean, 2002). In each cell, we first recorded a $5 \mathrm{~s}$ segment of spontaneous activity under current clamp and then used the recorded waveform as the command voltage after switching to voltageclamp mode in the same cell. Current carried through sodium channels was then isolated as the current sensitive to TTX, and current through calcium channels as the current sensitive to substitution of cobalt for calcium. Figure 5 shows results from such an experiment. As expected, sodium current was maximal during the upstroke of the action potential. However, there was also substantial sodium current during the spontaneous depolarization between spikes: it was near zero immediately after a spike (at the time of the afterhyperpolarization), but then gradually increased. The amplitude of sodium current during the interspike interval was measured at four different voltages in eight neurons and average values were $-1.3 \pm 0.4 \mathrm{pA}$ at $-60 \mathrm{mV},-2.6 \pm 0.5$ $\mathrm{pA}$ at $-55 \mathrm{mV},-6.0 \pm 1.4 \mathrm{pA}$ at $-50 \mathrm{mV}$, and $-13.6 \pm 2.5 \mathrm{pA}$ at $-45 \mathrm{mV}$ (Fig. 6A). The steep voltage dependence of TTX-
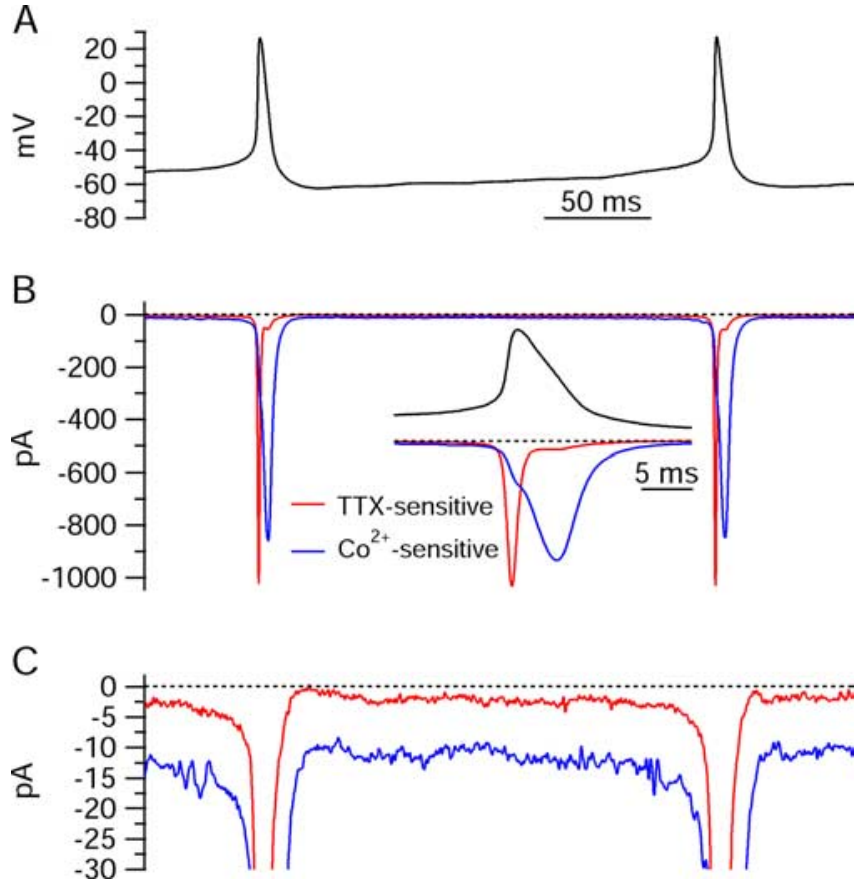

Figure 5. Tetrodotoxin-sensitive and cobalt-sensitive currents during the interspike interval in acutely dissociated SNc neurons determined using the action potential clamp technique. $\boldsymbol{A}$, Spontaneous firing in a dissociated dopaminergic neuron was recorded in whole-cell current clamp. This voltage waveform was then used in the same cell as a voltage command in voltage clamp. B, Ionic currents elicited by this waveform used as command voltage after switching the amplifier to voltage clamp mode. Sodium current (red trace) was obtained by subtracting currents elicited by the voltage command before and after application of $1 \mu \mathrm{m}$ TTX. Calcium current (blue trace) was obtained by subtracting currents elicited by the voltage command before and after replacement of calcium ions with equimolar cobalt. Inset, Sodium and calcium currents flowing during a single action potential on an expanded time scale. C, Sodium and calcium currents shown on expanded current scale. Currents were signal-averaged over $20-30$ repetitions of the voltage command.

sensitive sodium current over this voltage range (more than doubling for each change of $5 \mathrm{mV}$ ) is typical of subthreshold, "persistent" sodium current.

The current sensitive to replacement of extracellular calcium by cobalt was also determined. This current probably reflects predominantly current through voltage-dependent calcium channels, although in principle there could also be contributions from sources such as the sodium-calcium exchanger, voltageindependent calcium-permeant channels, or calcium-activated nonselective cation channels. As expected for current through voltage-activated calcium channels, cobalt-sensitive current was maximal during the falling phase of the action potential, including the shoulder of the action potential, consistent with previous arguments that calcium current plays an important role in the wide spike of the neurons. However, cobalt-sensitive current was also present throughout the interspike interval. Cobalt-sensitive current was larger than TTX-sensitive current at voltages negative to $-45 \mathrm{mV}$, and it was less steeply voltage-dependent over the range of interspike voltages. Also, unlike TTX-sensitive current, the cobalt-sensitive current was quite substantial even immediately after a spike. The average amplitude of the cobaltsensitive current (for the same eight neurons in which sodium current was quantified) was $-4.5 \pm 1.0 \mathrm{pA}$ at $-60 \mathrm{mV},-5.1 \pm$ $0.8 \mathrm{pA}$ at $-55 \mathrm{mV},-7.0 \pm 1.1 \mathrm{pA}$ at $-50 \mathrm{mV}$, and $-8.4 \pm 1.9 \mathrm{pA}$ at $-45 \mathrm{mV}$ (Fig. 6A). The relative contribution of TTX-sensitive and cobalt-sensitive currents to the spontaneous depolarization in between spikes was quantified (Fig. 6B) by integrating each 

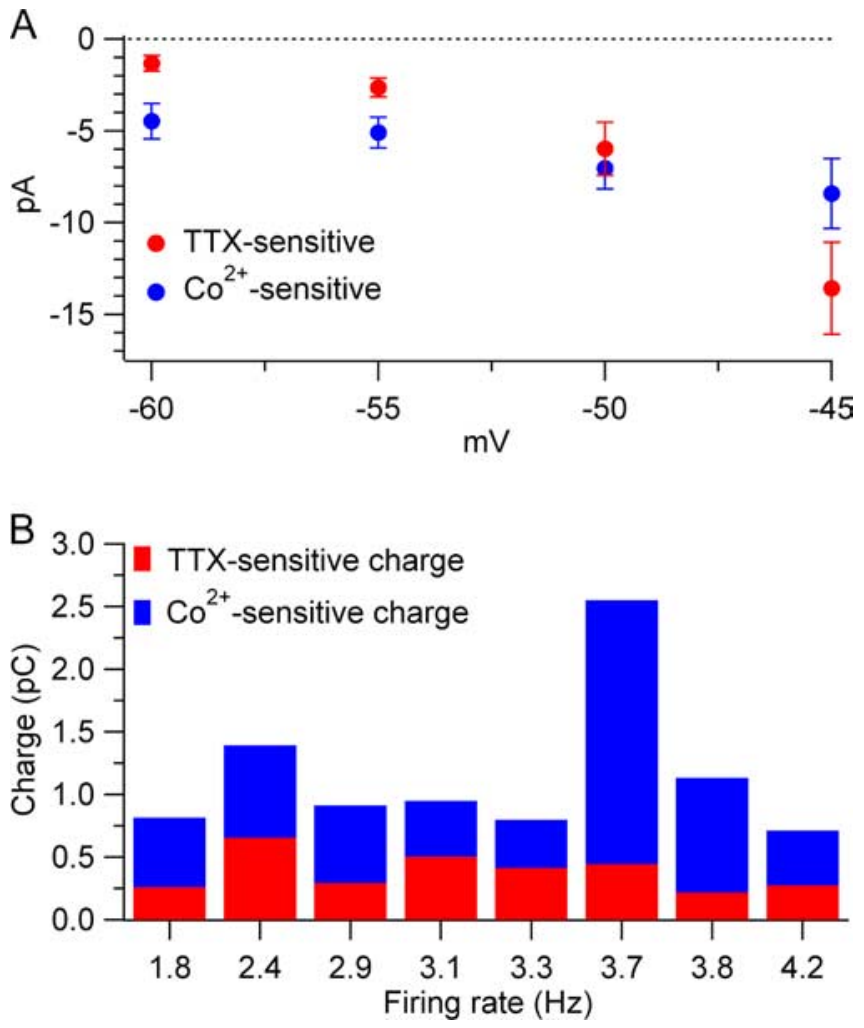

Figure 6. Comparison of current sensitive to cobalt substitution and TTX application in collected results from eight acutely dissociated SNc neurons. $A$, Current sensitive to TTX (red) and cobalt substitution (blue) during the interspike interval, averaged over eight neurons. Error bars show SEM. $\boldsymbol{B}$, The contribution of cobalt-sensitive currents (blue) and TTX-sensitive sodium currents (red) during the spontaneous interspike depolarization. Currents flowing during the interspike interval were integrated from the time of maximal afterhyperpolarization to the time at which voltage reached $-45 \mathrm{mV}$. In six of eight cells tested, the charge carried by calcium channels (blue bars) was bigger than the charge carried by sodium channels (red bars). Bars are stacked. Cells were arranged by their firing rate. There was no systematic correlation between firing rate and the relative contribution of sodium and calcium currents to the spontaneous interspike depolarization.

current from the time of the afterhyperpolarization $(-65.0 \pm 0.7$ $\mathrm{mV}$ in the eight neurons tested) to the time at which voltage reached $-45 \mathrm{mV}$, before spike threshold $(-41 \pm 1 \mathrm{mV}$ in the eight cells tested). In six of eight cells, the charge carried by cobalt-sensitive current during the interspike interval was larger than the charge carried by TTX-sensitive current, with no obvious correlation between the fractional contribution of the two currents and the firing rate. In collected results, the charge carried during the interspike interval by cobalt-sensitive current was $764 \pm 177 \mathrm{fC}$, and the charge carried by TTX-sensitive current was $345 \pm 60 \mathrm{fC}$, corresponding to an average of $57 \pm 13 \%$ of the charge carried by cobalt-sensitive current. These results suggest that both calcium and sodium currents contribute substantially to the spontaneous interspike depolarization, with calcium current carrying about twice as much charge as sodium current.

\section{Sodium and calcium currents during spikes}

Although our main goal was to examine the relative roles of calcium and sodium currents in driving spontaneous pacemaking, the experiments shown in Figure 5 are also useful for visualizing sodium and calcium currents during the various phases of the spike itself and for quantifying the total amount of calcium or sodium entering during a firing cycle. One surprise is the relative sizes of peak sodium current and calcium current during the spike (Fig. 5B): peak calcium current is not very much smaller than peak sodium current despite the much smaller concentration of external calcium (1.8 mM) compared with sodium (137 $\mathrm{mM}$ ), another indication of the unusually high density of calcium channels that appear to be present in SNc neurons. On average, peak calcium current (reached during the falling phase of the spike) was $61 \pm 8 \%(n=8)$ of the peak sodium current (reached during the upstroke). The large current carried by calcium during normal spikes is obviously consistent with the ability of calcium by itself to support fairly large spikes in neurons treated with TTX like that shown in Figure $4 B$. However, during normal spikes, the more rapid activation of the sodium current means that the calcium current makes only a minor contribution to the total inward current during the rising phase of the spike, amounting to only $7 \pm 2 \%$ of the sodium current at the same time. Thus, the rising phase of spikes is almost entirely attributable to sodium current during normal firing. During the shoulder of the action potential, however, calcium current was $12 \pm 4$-fold greater than sodium current, presumably because of nearly complete inactivation of sodium channels. Thus, sodium current clearly plays little role in supporting the shoulder of the spike in SNc neurons. This is in contrast to action potentials in nociceptors, which have similarly wide action potentials with shoulders, but where sodium currents play a greater role than calcium currents during the shoulder (Blair and Bean, 2002).

As another index of the large amount of calcium current entering SNc cells during spontaneous firing, we integrated the total cobalt-sensitive current entering during the spike (integrated from $-45 \mathrm{mV}$ just before the spike to the afterhyperpolarization). This amounted to $3534 \pm 744 \mathrm{fC}(n=8)$. This is both larger than the total TTX-sensitive sodium flux during the spike (1671 $\pm 151 \mathrm{fC})$ and also much larger than the calcium flux during the interspike interval $(764 \pm 177 \mathrm{fC})$. The total calcium flux during the entire firing cycle, as estimated by integrating cobalt-sensitive current, amounted to $4298 \pm 809 \mathrm{fC}$, much larger than the total TTX-sensitive sodium flux of $2017 \pm 165 \mathrm{fC}$.

\section{Interspike currents in slices}

The experiments so far were performed with acutely isolated neurons from relatively young animals (P14 to P18). To examine whether the results are likely to hold for more intact neurons from older animals, we also performed experiments using the action potential clamp method using cells studied in brain slice preparations from older (P35 to P42) animals. For these experiments, it was unnecessary to use transgenic animals, because dopaminergic neurons in the substantia nigra region of brain slices can be identified by their large cell bodies and regular, slow pacemaking with broad action potentials. Voltage-clamp experiments with intact cells must be interpreted cautiously, because both the uniformity and speed of voltage control are less good than in dissociated cells, but the limitations of voltage clamp should be least severe for the small, slowly changing currents between spikes that are of greatest interest. We were encouraged by previous evidence suggesting that the dendritic tree of dopaminergic neurons is reasonably electrotonically compact, at least between the cell body and the dendrite to which the initial segment of the axon is attached (Häusser et al., 1995). The results with the action potential clamp method applied to adult neurons in brain slice were similar to those obtained with dissociated neurons from younger animals with regard to the relative roles of calcium and sodium currents in driving spontaneous depolarization. Figure 7, $A$ and $B$, shows an example, and Figure $7 C$ shows average values for cobalt-sensitive and TTX-sensitive currents at various volt- 

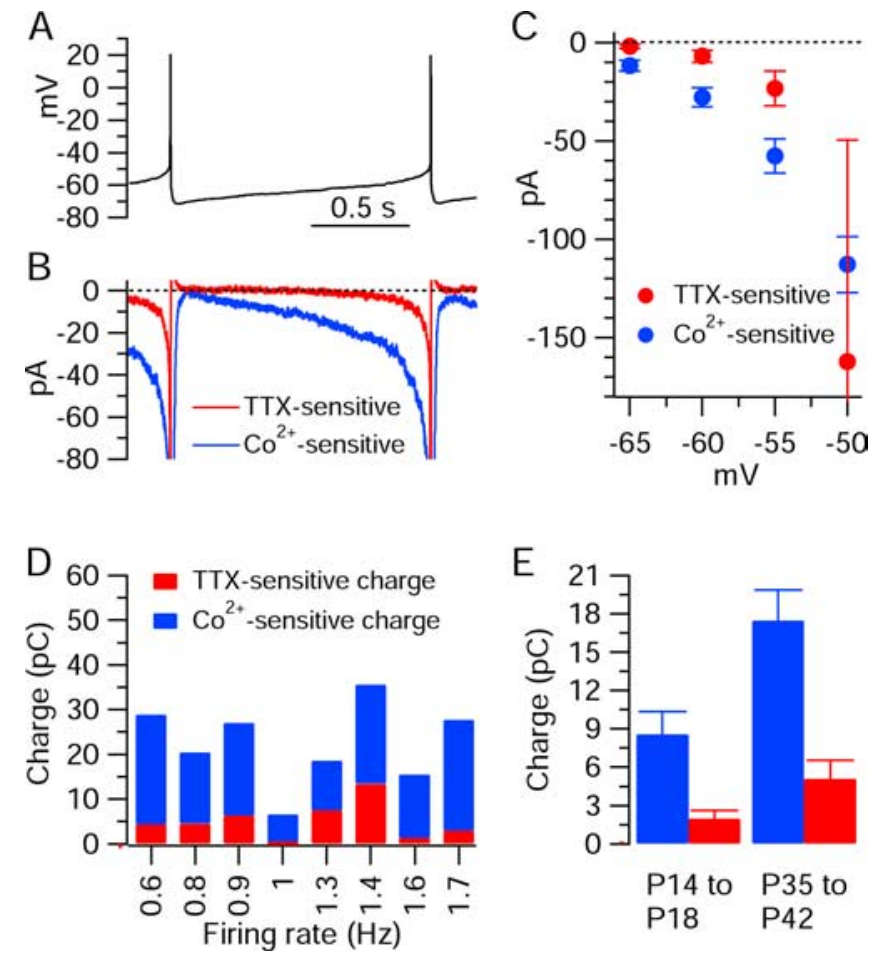

Figure 7. TTX-sensitive and cobalt-sensitive currents during the interspike interval in SNC neurons studied in brain slice. $A$, Spontaneous firing recorded in whole-cell current clamp in an SNc neuron in a brain slice preparation from an adult ( $42 \mathrm{~d}$ old) mouse. $\boldsymbol{B}$, TTX-sensitive and cobalt-sensitive currents elicited in voltage clamp in the same cell using the voltage waveform from spontaneous firing as voltage command. Currents were obtained by subtracting currents before and after application of $1 \mu \mathrm{m}$ TTX or before and after replacement of calcium ions with equimolar cobalt. C, Collected results comparing the relative contribution of TTX-sensitive and cobalt-sensitive currents during the interspike interval in eight SNc neurons studied in brain slices from 35- to 42-d-old mice. Symbols show mean \pm SEM for currents measured at -65 , $-60,-55$, and $-50 \mathrm{mV}$ during the interspike interval. $\boldsymbol{D}$, Cell-by-cell comparison of charge carried by TTX-sensitive (red) and cobalt-sensitive (blue) currents during the interspike interval, measured by integrating the currents from the time of the afterhyperpolarization to the time at which voltage reached $-50 \mathrm{mV}$. Cells are arranged by their firing rate, and bars are stacked. $\boldsymbol{E}$, Comparison of mean charge carried by sodium channels (red bar) and calcium channels (blue bar) in brain slices from young ( $14-18 \mathrm{~d}$ old) animals and from older ( $35-42 \mathrm{~d}$ old) animals. Error bars show mean \pm SEM for measurements from eight neurons in each age range.

ages during the interspike interval. Just as in dissociated neurons, interspike sodium current was very small immediately after spikes and increased with steep voltage-dependence during the interspike interval; average values for interspike sodium current were as follows: $-2.0 \pm 0.9 \mathrm{pA}$ at $-65 \mathrm{mV},-7.0 \pm 3.0 \mathrm{pA}$ at -60 $\mathrm{mV},-23.4 \pm 8.8 \mathrm{pA}$ at $-55 \mathrm{mV}$, and $-162.4 \pm 112.7 \mathrm{pA}$ at -50 $\mathrm{mV}(n=8)$. Also similar to dissociated neurons, cobalt-sensitive current was sizeable immediately after spikes and was larger than sodium current for most of the interspike interval (negative to $-50 \mathrm{mV}$ ). Average values for interspike cobalt-sensitive current were as follows: $-11.8 \pm 2.8 \mathrm{pA}$ at $-65 \mathrm{mV},-27.8 \pm 4.7 \mathrm{pA}$ at $-60 \mathrm{mV},-57.7 \pm 8.6 \mathrm{pA}$ at $-55 \mathrm{mV}$, and $-112.9 \pm 14.2 \mathrm{pA}$ at $-50 \mathrm{mV}$. As for the experiments in dissociated neurons, we quantified the relative contribution of TTX-sensitive and cobaltsensitive currents to the spontaneous depolarization in between spikes by integrating each current from the time of the afterhyperpolarization $(-74 \pm 2 \mathrm{mV}$ in the eight neurons tested) to the time at which voltage reached $-50 \mathrm{mV}$, before spike threshold (which was $-45 \pm 1 \mathrm{mV}$ in the eight cells tested). Integrated cobalt-sensitive current was larger than integrated interspike sodium current in each of the eight neurons tested. Thus, interspike calcium current appears to make a larger contribution than interspike sodium current in driving the spontaneous depolarization to threshold in adult neurons studied in brain slice, as it does in acutely dissociated neurons from young mice. In another series of experiments, we quantified interspike sodium and calcium currents in neurons studied in brain slices from younger animals (P14-P18, the same age as the dissociated neurons). Although integrated interspike sodium current and calcium current both increased between P14-P18 and P35-P42, their relative magnitudes showed little change (Fig. $7 E$ ), suggesting that there is little difference in relative roles of sodium current and calcium current in driving pacemaking as animals mature from $\mathrm{P} 14$ to $\mathrm{P} 42$. The relative contribution of charge from interspike sodium current was somewhat less in neurons studied in brain slice $(29 \pm 8 \%$ of cobalt-sensitive charge in P35-P42 neurons, $n=8 ; 23 \pm 5 \%$ of cobalt-sensitive charge in P14-P18 neurons, $n=11)$ compared with acutely dissociated neurons ( $57 \pm 13 \%$ of cobalt-sensitive charge; $n=8$ ). The difference is consistent with a relatively high density of calcium current in dendrites (Wilson and Callaway, 2000).

\section{Effects of selective calcium channel blockers}

Voltage-clamp experiments have shown that SNc neurons express multiple types of voltage-dependent calcium channels, including T-type, L-type, N-type, and P-type channels (Cardozo and Bean, 1995; Durante et al., 2004). We therefore tested the effect of subtype-specific calcium channel blockers. Because of the relatively slow time course of equilibration of the blockers compared with the instantaneous effect of cobalt substitution, it was not practical to perform action potential clamp experiments with subtype-specific blockers. Instead, we examined the effects of the blockers on spontaneous firing in current clamp in dissociated cells in which there was stable firing in control conditions. Blocking L-type calcium channels with $1 \mu \mathrm{M}$ nimodipine slowed spontaneous firing in nine of 17 neurons tested (Fig. $8 A, B$ ), with complete quiescence in four neurons. In those nine neurons, nimodipine caused a modest hyperpolarization (average interspike voltage from $-55.8 \pm 1.6$ to $-58.3 \pm 1.7 \mathrm{mV}$ ), a reduction of the firing rate from $3.3 \pm 0.3$ to $0.6 \pm 0.1 \mathrm{~Hz}$, an increase of the coefficient of variation of the interspike intervals from $45 \pm 9 \%$ to $124 \pm 16 \%$, and a reduction of the speed of the spontaneous depolarization in between spikes from $51 \pm 6 \mathrm{mV} / \mathrm{s}$ to $14 \pm 3$ $\mathrm{mV} / \mathrm{s}$. In the four neurons in which there was a complete cessation of firing in the presence of $1 \mu \mathrm{M}$ nimodipine, the drug caused a stronger hyperpolarization of the average interspike membrane potential, from $-54.5 \pm 3.0 \mathrm{mV}$ to $-66.7 \pm 2.9 \mathrm{mV}$, suggesting a major contribution of L-type calcium channels to the spontaneous interspike depolarization during the pacemaking cycle. The effects of nimodipine on firing in dissociated neurons are very similar to previous results with dihydropyridines applied to midbrain dopaminergic neurons in brain slice (Nedergaard et al., 1993; Mercuri et al., 1994).

In contrast to the effect of nimodipine, the N-type calcium channel blocker $\omega$-conotoxin GVIA $(3 \mu \mathrm{M})$ had no significant effect on spontaneous firing $(n=8)$ (data not shown). The drug had little or no effect on average interspike voltage $(-54.7 \pm 2.2$ $\mathrm{mV}$ in control, $-53.6 \pm 2.2 \mathrm{mV}$ with $3 \mu \mathrm{M} \omega$-conotoxin GVIA) or on firing rate $(2.8 \pm 0.3 \mathrm{~Hz}$ in control, $3.0 \pm 0.5 \mathrm{~Hz}$ with conotoxin), suggesting that $\mathrm{N}$-type calcium channels do not contribute inward current to the spontaneous interspike depolarization during the pacemaking cycle in SNc neurons. However, the P/Q-type calcium channel blocker $\omega$-Aga-IVA applied at $200 \mathrm{~nm}$ slowed spontaneous firing in 10 of 14 neurons tested (Fig. 9) with 

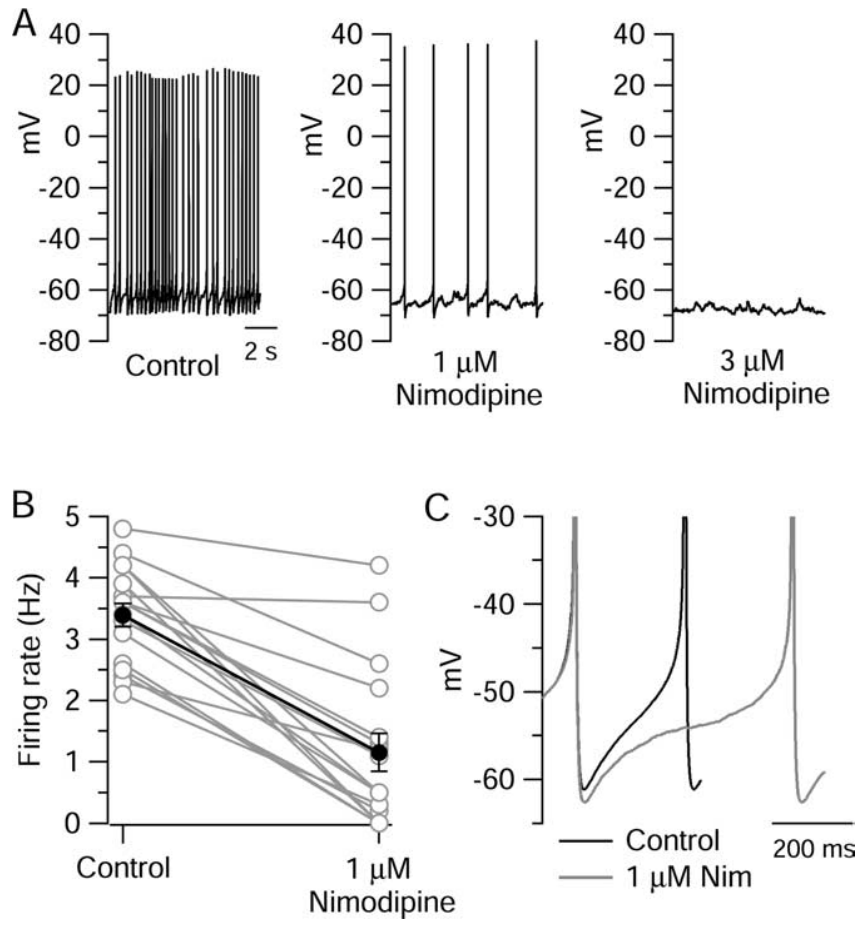

Figure 8. Effect of nimodipine on spontaneous firing in acutely dissociated SNc neurons. $\boldsymbol{A}_{t}$ Spontaneous firing in an SNc neuron in control (left), after application of $1 \mu \mathrm{m}$ nimodipine (middle), and after application of $3 \mu \mathrm{m}$ nimodipine (right). One micromolar nimodipine produced hyperpolarization of the membrane potential $(-2.1 \mathrm{mV})$ and reduction of the firing rate by $\sim 84 \%$. Three micromolars nimodipine produced additional hyperpolarization and silenced the cell. $\boldsymbol{B}$, Effect of $1 \mu \mathrm{m}$ nimodipine on the firing rate in each of the 17 cells tested (gray symbols). In averaged results (black symbols), $1 \mu \mathrm{m}$ nimodipine reduced firing rate by $68 \pm 8 \%$ $(n=17)$. C, Pacemaking cycle before (black) and after (gray) exposure of a neuron to $1 \mu \mathrm{m}$ nimodipine. Averaged pacemaking cycle was obtained by signal averaging over multiple cycles in each case, aligning spikes at their peak. Note the hyperpolarization of the membrane potential and increase in duration of the interspike interval produced by nimodipine.

cessation of firing in six neurons. In those 10 neurons, the drug caused a hyperpolarization of mean interspike voltage, from $-56.3 \pm 0.5 \mathrm{mV}$ to $-59.8 \pm 1.1 \mathrm{mV}$, a dramatic reduction of the firing rate from $4.5 \pm 0.5$ to $0.6 \pm 0.2 \mathrm{~Hz}$, an increase in the coefficient of variation of the interspike intervals from $39 \pm 12 \%$ to $138 \pm 19 \%$, and a decrease in the speed of the spontaneous depolarization in between spikes from $53 \pm 7 \mathrm{mV} / \mathrm{s}$ to $13 \pm 3$ $\mathrm{mV} / \mathrm{s}$. In the six neurons in which there was cessation of firing, the mean interspike membrane potential hyperpolarized more dramatically than in the other neurons, from $-56.0 \pm 1.0 \mathrm{mV}$ to $-62.1 \pm 1.5 \mathrm{mV}$.

\section{Discussion}

It is increasingly clear that multiple ionic mechanisms can produce spontaneous firing of different central neurons. The action potential clamp method has been used to quantify the interspike currents carried by calcium currents and TTX-sensitive sodium currents in a variety of pacemaking neurons. Of those neurons examined so far, $\mathrm{SNc}$ dopaminergic neurons are unique in having a larger calcium current than TTX-sensitive sodium current during the interspike interval. In contrast, interspike calcium current is $<10-25 \%$ of the interspike TTX-sensitive sodium current in cerebellar Purkinje neurons (Raman and Bean 1999), subthalamic nucleus neurons (Do and Bean, 2003), tuberomammillary nucleus neurons (Taddese and Bean, 2002) (A. Taddese and B. Bean, unpublished observation), and suprachiasmatic nucleus neurons (Jackson et al., 2004). Accordingly, inhibition of all cal-
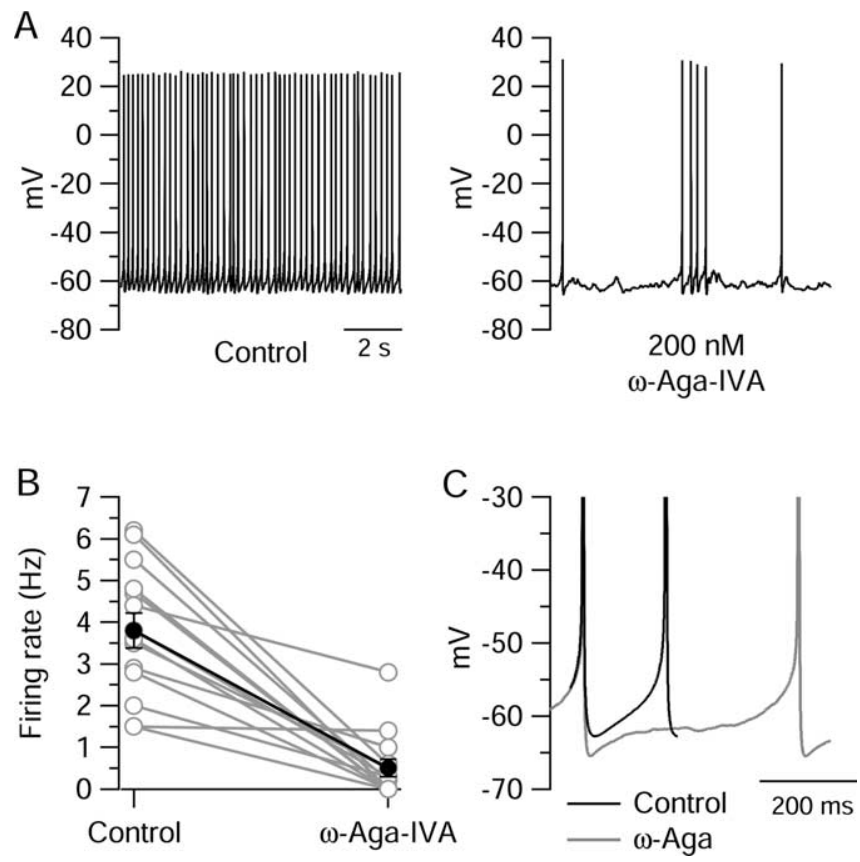

Figure 9. Effect of $\omega$-Aga-IVA on spontaneous firing in acutely dissociated SNc neurons. $A$, Spontaneous firing in an SNc neuron before (left) and after (right) application of $200 \mathrm{~nm} \omega$-AgaIVA. $\omega$-Aga-IVA produced a modest hyperpolarization $(-2 \mathrm{mV})$ and reduced firing rate by $\sim 90 \%$. B, Effect of $200 \mathrm{~nm} \omega$-Aga-IVA on the firing rate in each of 14 cells tested (gray symbols). In averaged results (black symbols), $200 \mathrm{~nm} \omega$-Aga-IVA reduced firing rate by $83 \pm 8 \%$ $(n=14)$. C, Signal-averaged pacemaking cycle before (black) and after (gray) exposure of a neuron to $200 \mathrm{~nm} \omega$-Aga-IVA. Note the hyperpolarization of the membrane potential and increase in duration of the interspike interval caused by $200 \mathrm{~nm} \omega$-Aga-IVA.

cium current in these neurons (e.g., by substituting cobalt or magnesium for calcium) generally does not stop spontaneous firing although it sometimes decreases regularity of firing, probably by inhibiting calcium-activated potassium currents (Hallworth et al., 2004; Walter et al., 2006). Interestingly, the cells with the largest contribution of calcium entry studied previously are dopaminergic periglomerular neurons in the olfactory bulb, where interspike calcium current is on average $\sim 70 \%$ of interspike sodium current (Puopolo et al., 2005), and where replacing calcium by cobalt results in cessation of firing accompanied by hyperpolarization (Pignatelli et al., 2005; Puopolo et al., 2005), as we saw in the SNc dopaminergic neurons. Substitution of cobalt for calcium also hyperpolarizes and silences spontaneously active cholinergic interneurons (Bennett et al., 2000); here, however, the effect can be attributed to reduction of $I_{\mathrm{h}}$ current and other evidence suggests a minor direct role of subthreshold calcium entry in driving pacemaking. Changes in $I_{\mathrm{h}}$ cannot account for the effects of cobalt substitution in our experiments, because total block of $I_{\mathrm{h}}$ at most slowed firing only moderately (and often did nothing), whereas cobalt substitution silenced all cells.

The simplest interpretation of the interspike current sensitive to cobalt substitution for calcium is that it represents calcium current flowing directly through calcium-permeable channels. In this case, the effect of nimodipine in slowing or blocking spontaneous firing can most simply be attributed to block of L-type calcium current flowing during the interspike interval. Such a direct effect is consistent with the net hyperpolarization during the interspike interval produced by nimodipine, which contrasts with the net interspike depolarization and reduction of afterhyperpolarization seen in suprachiasmatic nucleus neurons, apparently reflecting indirect block of calcium-activated potassium 
current (Cloues and Sather, 2003; Jackson et al., 2004). Interspike L-type current in SNc dopaminergic neurons is consistent with previous evidence that the calcium channels contributing to pacemaking activate at potentials as negative as $-60 \mathrm{mV}$ and show little inactivation (Kang and Kitai, 1993b; Wilson and Callaway, 2000). Midbrain dopaminergic neurons express $\mathrm{Ca}_{\mathrm{V}} 1.3$ calcium channels (Takada et al., 2001) (D. J. Surmeier, personal communication), which activate at more negative voltages than L-type current carried by $\mathrm{Ca}_{\mathrm{V}} 1.2$ calcium channels (Koschak et al., 2001; Scholze et al., 2001; Xu and Lipscombe, 2001). Durante et al. (2004) found that the L-type current in dissociated dopaminergic neurons activates at more negative potentials than $\mathrm{N}$-type and $\mathrm{P} / \mathrm{Q}$-type currents, consistent with a contribution by $\mathrm{Ca}_{\mathrm{V}} 1.3$ channels.

Although calcium current appears to play a dominant role in driving spontaneous depolarization, subthreshold sodium current is also significant during the interspike interval, amounting on average to $\sim 60 \%$ of the cobalt-sensitive current. The participation of subthreshold, persistent sodium current in helping to drive pacemaking has been suggested before and is embodied in models of pacemaking of dopaminergic neurons as contributing to the spontaneous depolarization without being essential (Kuznetsov et al., 2006), as our results support.

Because SNc neurons have subthreshold persistent sodium current, which by itself appears sufficient to drive pacemaking of many types of neurons that lack significant subthreshold calcium current and fire much faster than SNc dopaminergic neurons (Taddese and Bean, 2002; Atherton and Bevan, 2005), why is it that blocking calcium current silences SNc neurons? The key factor is most likely the resting potential (i.e., the voltage reached when spontaneous activity is silenced), which in our experiments was about $-65 \mathrm{mV}$ when neurons were silenced by TTX or by cobalt substitution for calcium. This is negative to the voltage at which persistent sodium current typically becomes significant, about -60 to $-55 \mathrm{mV}$ (Bennett et al., 2000; Taddese and Bean, 2002). In contrast, many neurons whose pacemaking depends mainly on persistent sodium current have resting potentials in the range from -55 to $-45 \mathrm{mV}$ when silenced by TTX (Raman et al., 2000; Taddese and Bean, 2002; Atherton and Bevan, 2005), so that no other subthreshold current is necessary to produce a spontaneous depolarization. Several such neurons have been shown to possess a non-TTX-sensitive resting sodium conductance that contributes to a depolarized resting potential (Raman et al., 2000; Eggermann et al., 2003; Jackson et al., 2004; Atherton and Bevan, 2005). We can speculate that the expression of the channels underlying this conductance, which are not known, is lower in SNc neurons than in the pacemaking neurons that can fire spontaneously using only persistent sodium current.

Overall, our results fit well with a current model of spontaneous firing of midbrain dopaminergic neurons in which both soma and dendritic branches have intrinsic oscillatory activity based on subthreshold calcium current (Wilson and Callaway, 2000; Medvedev et al., 2003; Kuznetsov et al., 2006). However, it is unexpected that the isolated cell bodies show more rapid pacemaking than intact cells, because the model, supported by experimental evidence from calcium imaging (Wilson and Callaway, 2000), envisions a system of coupled oscillators (coupled by voltage) in which the dendrites have faster natural frequencies of oscillation than the cell body. The firing of dissociated cells clearly occurs mainly by subthreshold calcium current, as proposed in the model. One possible explanation of its unexpected speed would be if either calcium-activated or voltage-activated potassium currents had a lower density in the cell body compared with dendrites, which could allow faster recovery from the afterhyperpolarization. Block of calcium-activated SK channels in dopaminergic neurons both speeds firing and also decreases the regularity of spontaneous firing (Ping and Shepard, 1996; Wolfart et al., 2001). Consistent with reduced influence of SK current in cell bodies, the firing in our experiments was considerably less regular (coefficient of variation of interspike intervals of 45\%) than that seen in intact neurons ( 10\%) (Wolfart et al., 2001). This suggests that the system of coupled oscillators with intact dendrites serves to enhance the precision of firing (Wilson and Callaway, 2000). Regional differences in channel density between soma and dendrites are common in other neuronal types but have not been systematically examined in dopaminergic neurons.

Another unexpected result is the large magnitude of calcium entry during the action potential compared with the subthreshold current entering during the phase of spontaneous depolarization: $80 \%$ of the total calcium entry during the pacemaking cycle occurs during the spike. This is surprising because in calciumimaging experiments, the signal from calcium entry decreases only slightly when fast spikes are blocked by TTX (Wilson and Callaway, 2000). However, the two sets of observations are not necessarily incompatible, because the calcium spikes occurring in TTX, although much smaller than normal fast spikes, are also much broader, and it is possible that equivalent calcium entry occurs with slower kinetics (and possibly through a different mixture of channels).

Perhaps the most surprising result in our experiments was the dramatic slowing of firing produced by $\omega$-Aga-IVA. This is unexpected because $\omega$-Aga-IVA appears to be a highly selective blocker of $\mathrm{Ca}_{\mathrm{V}} 2.1$ (P/Q-type) channels, which require relatively large depolarizations to be activated. Indeed, previous voltageclamp experiments in dissociated dopaminergic neurons have shown that $\omega$-Aga-IVA blocks a distinct fraction of highthreshold activated calcium current (Cardozo and Bean, 1995; Durante et al., 2004), and there is no hint that the $\omega$-Aga-IVAsensitive current includes a subthreshold component. In particular, it seems clear that $\omega$-Aga-IVA does not also inhibit lowthreshold L-type current through a nonselective action because the fraction of total current blocked by $\omega$-Aga-IVA is similar whether or not cells were previously exposed to nimodipine and vice versa (Durante et al., 2004). An interesting possibility is that the effect of $\omega$-Aga-IVA on pacemaking is indirectly mediated as a consequence of block of spike-evoked calcium entry through $\omega$-Aga-IVA-sensitive channels. Recent experiments on pacemaking cells in the cardiac sinoatrial node have suggested a major role for depolarizing current produced by the $\mathrm{Na} / \mathrm{Ca}$ exchanger as it pumps calcium that enters during the pacemaking cycle (Sanders et al., 2006). It is becoming clear that, like cardiac sinoatrial cells, pacemaking of midbrain dopaminergic neurons involves massive entry of calcium during both the slow spontaneous depolarization and also during the spike. The consequences and mechanisms for removal of this unusually large calcium entry remain to be characterized in more detail and could well be involved in the unique pathophysiology of these neurons.

\section{References}

Astman N, Gutnick MJ, Fleidervish IA (2006) Persistent sodium current in layer 5 neocortical neurons is primarily generated in the proximal axon. J Neurosci 26:3465-3473.

Atherton JF, Bevan MD (2005) Ionic mechanisms underlying autonomous action potential generation in the somata and dendrites of GABAergic substantia nigra pars reticulata neurons in vitro. J Neurosci 25:8272-8281.

Banerjee SA, Hoppe P, Brilliant M, Chikaraishi DM (1992) 5' flanking se- 
quences of the rat tyrosine hydroxylase gene target accurate tissuespecific, developmental, and transsynaptic expression in transgenic mice. J Neurosci 12:4460-4467.

Bennett BD, Callaway JC, Wilson CJ (2000) Intrinsic membrane properties underlying spontaneous tonic firing in neostriatal cholinergic interneurons. J Neurosci 20:8493-8503.

Beurrier C, Bioulac B, Hammond C (2000) Slowly inactivating sodium current $(\mathrm{I}(\mathrm{NaP}))$ underlies single-spike activity in rat subthalamic neurons. J Neurophysiol 83:1951-1957.

Bevan MD, Wilson CJ (1999) Mechanisms underlying spontaneous oscillation and rhythmic firing in rat subthalamic neurons. J Neurosci 19:7617-7628.

Blair NT, Bean BP (2002) Roles of tetrodotoxin (TTX)-sensitive $\mathrm{Na}^{+}$current, TTX-resistant $\mathrm{Na}^{+}$current, and $\mathrm{Ca}^{2+}$ current in the action potentials of nociceptive sensory neurons. J Neurosci 22:10277-10290.

Cardozo DL, Bean BP (1995) Voltage-dependent calcium channels in rat midbrain dopamine neurons: modulation by dopamine and GABAB receptors. J Neurophysiol 74:1137-1148.

Cloues RK, Sather WA (2003) Afterhyperpolarization regulates firing rate in neurons of the suprachiasmatic nucleus. J Neurosci 23:1593-1604.

Dauer W, Przedborski S (2003) Parkinson's disease: mechanisms and models. Neuron 39:889-909.

De Groote G, De Waele P, Van de Voorde A, De Broe M, Fiers W (1983) Use of monoclonal antibodies to detect human placental alkaline phosphatase. Clin Chem 29:115-119.

Do MT, Bean BP (2003) Subthreshold sodium currents and pacemaking of subthalamic neurons: modulation by slow inactivation. Neuron 39:109-120.

Durante P, Cardenas CG, Whittaker JA, Kitai ST, Scroggs RS (2004) Lowthreshold L-type calcium channels in rat dopamine neurons. J Neurophysiol 91:1450-1454.

Eggermann E, Bayer L, Serafin M, Saint-Mleux B, Bernheim L, Machard D, Jones BE, Muhlethaler M (2003) The wake-promoting hypocretinorexin neurons are in an intrinsic state of membrane depolarization. J Neurosci 23:1557-1562.

Feigenspan A, Gustincich S, Bean BP, Raviola E (1998) Spontaneous activity of solitary dopaminergic cells of the retina. J Neurosci 18:6776-6789.

Fujimura K, Matsuda Y (1989) Autogenous oscillatory potentials in neurons of the guinea pig substantia nigra pars compacta in vitro. Neurosci Lett 10453-57.

Grace AA, Bunney BS (1984) The control of firing pattern in nigral dopamine neurons: single spike firing. J Neurosci 4:2866-2876.

Grace AA, Onn SP (1989) Morphology and electrophysiological properties of immunocytochemically identified rat dopamine neurons recorded in vitro. J Neurosci 9:3463-3481.

Gustincich S, Feigenspan A, Wu DK, Koopman LJ, Raviola E (1997) Control of dopamine release in the retina: a transgenic approach to neural networks. Neuron 18:723-736.

Hainsworth AH, Roper J, Kapoor R, Ashcroft FM (1991) Identification and electrophysiology of isolated pars compacta neurons from guinea-pig substantia nigra. Neuroscience 43:81-93.

Hallworth NE, Wilson CJ, Bevan MD (2004) Apamin-sensitive small conductance calcium-activated potassium channels, through their selective coupling to voltage-gated calcium channels, are critical determinants of the precision, pace, and pattern of action potential generation in rat subthalamic nucleus neurons in vitro. J Neurosci 23:7525-7542.

Harris NC, Webb C, Greenfield SA (1989) A possible pacemaker mechanism in pars compacta neurons of the guinea-pig substantia nigra revealed by various ion channel blocking agents. Neuroscience 31:355-362.

Häusser M, Stuart G, Racca C, Sakmann B (1995) Axonal initiation and active dendritic propagation of action potentials in substantia nigra neurons. Neuron 15:637-647.

Jackson AC, Yao GL, Bean BP (2004) Mechanism of spontaneous firing in dorsomedial suprachiasmatic nucleus neurons. J Neurosci 24:7985-7998.

Kang Y, Kitai ST (1993a) A whole cell patch-clamp study on the pacemaker potential in dopaminergic neurons of rat substantia nigra compacta. Neurosci Res 18:209-221.

Kang Y, Kitai ST (1993b) Calcium spike underlying rhythmic firing in dopaminergic neurons of the rat substantia nigra. Neurosci Res 18:195-207.

Kole MH, Hallermann S, Stuart GJ (2006) Single Ih channels in pyramidal neuron dendrites: properties, distribution, and impact on action potential output. J Neurosci 26:1677-1687.
Koob GF, Sanna PP, Bloom FE (1998) Neuroscience of addiction. Neuron 21:467-476.

Koschak A, Reimer D, Huber I, Grabner M, Glossmann H, Engel J, Striessnig J (2001) $\alpha 1 \mathrm{D}$ (Cav1.3) subunits can form 1-type $\mathrm{Ca}^{2+}$ channels activating at negative voltages. J Biol Chem 276:22100-22106.

Kuznetsov AS, Kopell NJ, Wilson CJ (2006) Transient high-frequency firing in a coupled-oscillator model of the mesencephalic dopaminergic neuron. J Neurophysiol 95:932-947.

Lewis DA, Lieberman JA (2000) Catching up on schizophrenia: natural history and neurobiology. Neuron 28:325-334.

Llinás R, Alonso A (1992) Electrophysiology of the mammillary complex in vitro. I. Tuberomammillary and lateral mammillary neurons. J Neurophysiol 68:1307-1320.

Llinás R, Sugimori M, Simon SM (1982) Transmission by presynaptic spike-like depolarization in the squid giant synapse. Proc Natl Acad Sci USA 79:2415-2419.

Lorincz A, Notomi T, Tamas G, Shigemoto R, Nusser Z (2002) Polarized and compartment-dependent distribution of HCN1 in pyramidal cell dendrites. Nat Neurosci 5:1185-1193.

Magee JC (1998) Dendritic hyperpolarization-activated currents modify the integrative properties of hippocampal CAl pyramidal neurons. J Neurosci 18:7613-7624.

Magistretti J, Mantegazza M, Guatteo E, Wanke E (1996) Action potentials recorded with patch-clamp amplifiers: are they genuine? Trends Neurosci 19:530-534.

Magistretti J, Mantegazza M, de Curtis M, Wanke E (1998) Modalities of distortion of physiological voltage signals by patch-clamp amplifiers: a modeling study. Biophys J 74:831-842.

Medvedev GS, Wilson CJ, Callaway JC, Kopell N (2003) Dendritic synchrony and transient dynamics in a coupled oscillator model of the dopaminergic neuron. J Comput Neurosci 15:53-69.

Mercuri NB, Bonci A, Calabresi P, Stratta F, Stefani A, Bernardi G (1994) Effects of dihydropyridine calcium antagonists on rat midbrain dopaminergic neurones. Br J Pharmacol 113:831-838.

Mercuri NB, Bonci A, Calabresi P, Stefani A, Bernardi G (1995) Properties of the hyperpolarization-activated cation current Ih in rat midbrain dopaminergic neurons. Eur J Neurosci 7:462-469.

Mintz IM, Adams ME, Bean BP (1992) P-type calcium channels in central and peripheral neurons. Neuron 9:1-20.

Nedergaard S, Greenfield SA (1992) Sub-populations of pars compacta neurons in the substantia nigra: the significance of qualitatively and quantitatively distinct conductances. Neuroscience 48:423-437.

Nedergaard S, Flatman JA, Engberg I (1993) Nifedipine- and omegaconotoxin-sensitive $\mathrm{Ca}^{2+}$ conductances in guinea-pig substantia nigra pars compacta neurones. J Physiol (Lond) 466:727-747.

Neher E (1992) Correction for liquid junction potentials in patch clamp experiments. Methods Enzymol 207:123-131.

Neuhoff H, Neu A, Liss B, Roeper J (2002) I(h) channels contribute to the different functional properties of identified dopaminergic subpopulations in the midbrain. J Neurosci 22:1290-1302.

Nieoullon A (2002) Dopamine and the regulation of cognition and attention. Prog Neurobiol 67:53-83.

Pennartz CM, Bierlaagh MA, Geurtsen AM (1997) Cellular mechanisms underlying spontaneous firing in rat suprachiasmatic nucleus: involvement of a slowly inactivating component of sodium current. J Neurophysiol 78:1811-1825.

Pignatelli A, Kobayashi K, Okano H, Belluzzi O (2005) Functional properties of dopaminergic neurones in the mouse olfactory bulb. J Physiol (Lond) 564:501-514.

Ping HX, Shepard PD (1996) Apamin-sensitive $\mathrm{Ca}^{2+}$-activated $\mathrm{K}^{+}$channels regulate pacemaker activity in nigral dopamine neurons. NeuroReport 7:809-814.

Puopolo M, Bean BP, Raviola E (2005) Spontaneous activity of isolated dopaminergic periglomerular cells of the main olfactory bulb. J Neurophysiol 94:3618-3627.

Raman IM, Bean BP (1999) Ionic currents underlying spontaneous action potentials in isolated cerebellar Purkinje neurons. J Neurosci 19:1663-1674.

Raman IM, Gustafson AE, Padgett D (2000) Ionic currents and spontaneous firing in neurons isolated from the cerebellar nuclei. J Neurosci 20:9004-9016.

Sanders L, Rakovic S, Lowe M, Mattick PA, Terrar DA (2006) Fundamental 
importance of $\mathrm{Na}^{+}-\mathrm{Ca}^{2+}$ exchange for the pacemaking mechanism in guinea-pig sino-atrial node. J Physiol (Lond) 571:639-649.

Scholze A, Plant TD, Dolphin AC, Nurnberg B (2001) Functional expression and characterization of a voltage-gated CaV1.3 (alpha1D) calcium channel subunit from an insulin-secreting cell line. Mol Endocrinol 15:1211-1221.

Schultz W (2002) Getting formal with dopamine and reward. Neuron 36:241-263.

Seutin V, Massotte L, Renette MF, Dresse A (2001) Evidence for a modulatory role of Ih on the firing of a subgroup of midbrain dopamine neurons. NeuroReport 12:255-258.

Steffen MA, Seay CA, Amini B, Cai Y, Feigenspan A, Baxter DA, Marshak DW (2003) Spontaneous activity of dopaminergic retinal neurons. Biophys J $85: 2158-2169$.

Taddese A, Bean BP (2002) Subthreshold sodium current from rapidly inactivating sodium channels drives spontaneous firing of tuberomammillary neurons. Neuron 33:587-600.

Takada M, Kang Y, Imanishi M (2001) Immunohistochemical localization of voltage-gated calcium channels in substantia nigra dopamine neurons. Eur J Neurosci 13:757-762.

Takakusaki K, Kitai ST (1997) Ionic mechanisms involved in the spontaneous firing of tegmental pedunculopontine nucleus neurons of the rat. Neuroscience 78:771-794.
Walter JT, Alvina K, Womack MD, Chevez C, Khodakhah K (2006) Decreases in the precision of Purkinje cell pacemaking cause cerebellar dysfunction and ataxia. Nat Neurosci 9:389-397.

Williams SR, Stuart GJ (2000) Site independence of EPSP time course is mediated by dendritic Ih in neocortical pyramidal neurons. J Neurophysiol 83:3177-3182.

Wilson CJ, Callaway JC (2000) Coupled oscillator model of the dopaminergic neuron of the substantia nigra. J Neurophysiol 83:3084-3100.

Wise RA (2004) Dopamine, learning and motivation. Nat Rev Neurosci 5:483-494.

Wolfart J, Neuhoff H, Franz O, Roeper J (2001) Differential expression of the small-conductance, calcium-activated potassium channel SK3 is critical for pacemaker control in dopaminergic midbrain neurons. J Neurosci 21:3443-3456.

Xu W, Lipscombe D (2001) Neuronal Ca $\mathrm{Ca}_{\mathrm{V}} 1.3_{\alpha 1}$ L-type channels activate at relatively hyperpolarized membrane potentials and are incompletely inhibited by dihydropyridines. J Neurosci 21:5944-5951.

Yung WH, Hausser MA, Jack JJ (1991) Electrophysiology of dopaminergic and non-dopaminergic neurones of the guinea-pig substantia nigra pars compacta in vitro. J Physiol (Lond) 436:643-667.

Zaza A, Micheletti M, Brioschi A, Rocchetti M (1997) Ionic currents during sustained pacemaker activity in rabbit sino-atrial myocytes. J Physiol (Lond) 505:677-688. 